University of Louisville

ThinkIR: The University of Louisville's Institutional Repository

Electronic Theses and Dissertations

$5-2021$

\title{
Exploring socialization processes for leisure-based esports: a qualitative study.
}

Joseph R. Brewer

University of Louisville

Follow this and additional works at: https://ir.library.louisville.edu/etd

Part of the Other Sociology Commons, and the Sports Studies Commons

\section{Recommended Citation}

Brewer, Joseph R., "Exploring socialization processes for leisure-based esports: a qualitative study." (2021). Electronic Theses and Dissertations. Paper 3621.

https://doi.org/10.18297/etd/3621

This Master's Thesis is brought to you for free and open access by ThinkIR: The University of Louisville's Institutional Repository. It has been accepted for inclusion in Electronic Theses and Dissertations by an authorized administrator of ThinkIR: The University of Louisville's Institutional Repository. This title appears here courtesy of the author, who has retained all other copyrights. For more information, please contact thinkir@louisville.edu. 


\title{
EXPLORING SOCIALIZATION PROCESSES FOR LEISURE-BASED ESPORTS: A
} QUALITATIVE STUDY

\author{
By \\ Joseph R Brewer \\ B.A. University of Louisville, 2019 \\ A Thesis \\ Submitted to the Faculty of the \\ College of Arts and Sciences of the University of Louisville \\ in Partial Fulfillment of the Requirements \\ for the Degree of
}

\author{
Master of Arts \\ in Sociology
}

\begin{abstract}
Department of Sociology
University of Louisville

Louisville, Kentucky
\end{abstract}

May 2021 

EXPLORING SOCIALIZATION PROCESSES FOR LEISURE-BASED ESPORTS: A QUALITATIVE STUDY

\author{
By \\ Joseph Brewer \\ B.A. University of Louisville, 2019
}

A Thesis Approved on

April 14, 2021

by the following Thesis Committee:

Dr. Robert Carini

Dr. Karen Christopher

Dr. Mark Austin 


\section{ABSTRACT \\ EXPLORING SOCIALIZATION PROCESSES FOR LEISURE-BASED ESPORTS: A QUALITATIVE STUDY}

Joseph Brewer

April 14, 2021

This study analyzed the perspectives of leisure-based esports participants from a Facebook group dedicated to a popular fighting game as esports. This study used a grounded theoretical approach, and several orienting theories/concepts (Serious Leisure, Recreation Specialization, social worlds, and the performance ethic) were used to study socialization into - and through - leisure-based esports participation. Based on ten interviews conducted from September through October 2020, this study found that if individuals were introduced to esports from the performance ethic, they tended to be socialized into social themes associated with the activity and vice versa. Through esports, participants were taught thoughts, actions, and feelings applicable to, both the social world(s) of esports and their outside lives. Participants displayed the hallmarks of serious leisure, as well as stages of increased specialization in esports. This study suggests opportunities for future studies to explore leisure-based esports, meanings of participation for participants, and linkages to professional esports. 


\section{TABLE OF CONTENTS}

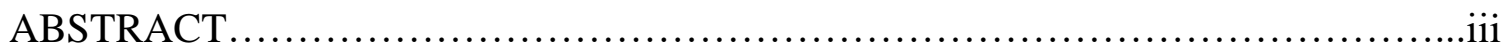

INTRODUCTION \& OBJECTIVES ...............................................

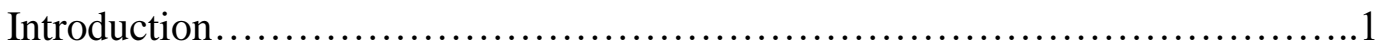

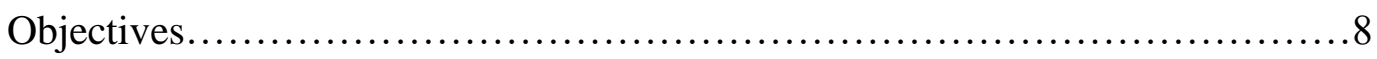

METHODOLOGY \& DATA ANALYSIS ...................................... 10

Group Interactions Prior to the COVID-19 Pandemic............................12

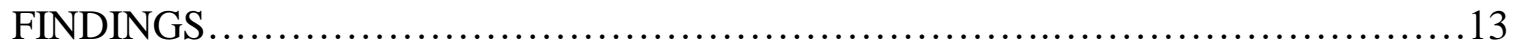

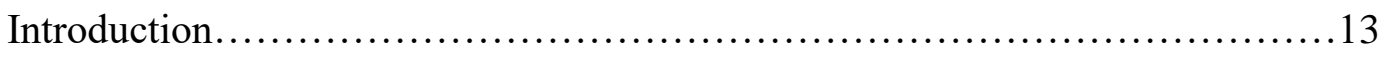

Socialization Into Leisure-Based Esports..................................13

Socialization Through Leisure-Based Esports..................................19

Specialization Within Leisure-Based Esports..............................24

SLP Categorization of Participation in Leisure-Based Esports....................29

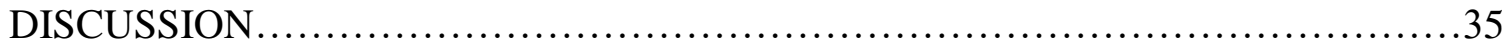

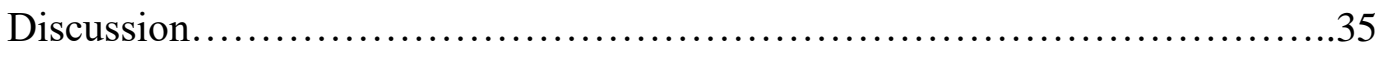

The Value of this Study ................................................. 43

LIMITATIONS \& FUTURE RESEARCH.........................................44

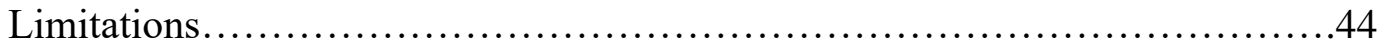

Future Research....................................................... 45

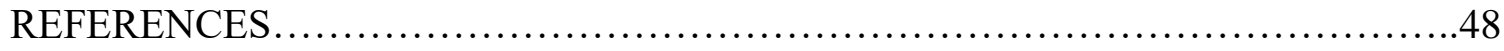

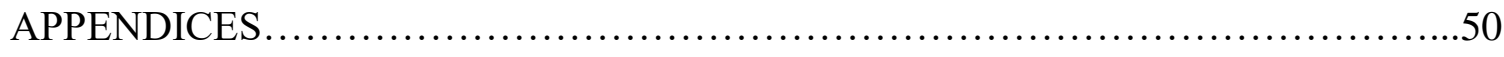

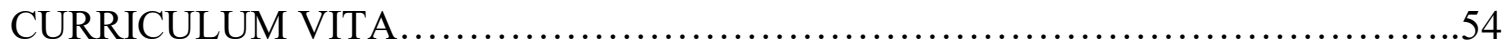




\section{INTRODUCTION \& OBJECTIVES}

\section{Introduction}

Since the turn of the century, esports has transformed from a fringe activity performed by only a select subculture, starting with one of the earliest official tournaments in 1972 known as the "Spacewar Olympics" by Stewart Brand of Rolling Stone magazine, into a mainstream global phenomenon that brings in billions of dollars in revenue each year (Taylor 2012). Esports' rise has also occurred alongside social media's rise and the two may be intrinsically linked. What was once restricted to private homes or small events now fill stadiums across the globe and allows those at the top of the field to live off their winnings, sponsorships, and participation (Taylor 2012). With the rise of esports in prominence came studies, but current studies have been limited to professional events, those desiring to be professional esports competitors, and the nonparticipants (people who do not participate in esports but help those who do) in their lives [T.L. Taylor (2012) and Nicholas Thiel Taylor (2016)]. Current studies have only superficially considered esports as a recreational or leisure activity for the participant and they have not been conducted solely via studying individuals who participate in esports as a hobby.

For these types of people, their love of gaming has bloomed into a hobby that may be a major part of their lives (Taylor 2012). Most individuals who classify themselves as gamers do not spend all of their time playing only one game. Instead, they move around from game to game and experience to experience. Those who participate in esports 
though have a dedication to one singular game or a select few at most (Taylor 2016). This dedication manifests itself in practice and competition. This study analyzed what esports means to those who do not participate as professionals; specifically, this study analyzed individuals who participate in leisure-based esports.

Leisure and recreation are interchangeable terms for many scholars and writers. But others, including this study, make a distinction between them. Leisure is a broad term that commonly invokes the dimensions of free time, enjoyable activities, and a state of mind or being. Leisure is a multidimensional construct in where a participant is free from or overcomes constraints, affects the participant, is motivated by internal forces and/or external forces, and allows the demonstration of competence (Edginton et al. 2002). Recreation is narrower and more focused than leisure:

Recreation is undertaken for conscious or unconscious end results. These ends might include benefits such as relaxation, stress relief, or creative expression. Recreation can be viewed as a means to an end. For example, a person might take a walk to see the beauty of wildflowers. Generally, recreation is associated with activities that are voluntary, organized, socially redeeming, and fun and that occur during free time. Recreation generally involves participation in an activity, whether a physical activity such as basketball or hiking or a passive activity such as picnicking or seeing a movie. (Henderson 2010:7-8).

Esports participation may or may not meet the criteria to be classified as recreation. Esports participation may be a means to an end for some participants but not for others. For example, some participants may get into esports to achieve a level of fame in the scene, but others just want to compete (Taylor 2016). It also may not involve net benefits or be socially redeeming. Lastly, esports participation may or may not be classified as physical activity. However, these are general guidelines and not strict requirements, as such esports might meet the criteria to be recreation, but there is no 
question that esports participation does meet the criteria for leisure. Therefore, for this study esports will be considered leisure, and thus leisure-based esports or esports will be the terms used.

Scholars such as T.L. Taylor (2012) and Nicholas Thiel Taylor (2016) focused on the transformation of esports from casual gaming into a competitive sport. Burk (2013), Carlson (2018), and Freeman \& Wohn. (2018) debated whether esports is a form of sports or if the debate should even exist at all, while this study focuses on leisure-based participation in esports. Specifically, this study looked at the socialization of individuals into and through their participation in esports (Kleiber et al. 2011).

Although some view competitive gaming for leisure as a physically isolating activity, for many players this activity pushes them to meet others in person, to create new friendships, and to step out of their homes to go to events as seen in Taylor's (2012) work. Via engaging in these events, they become socialized through their participation and over time create roles for themselves to fulfill and identities based around their participation (Taylor 2012). There is room to build upon the studies conducted on esports and many questions can still be asked. Socialization into an activity for this study followed the definition put forth by Mannell \& Kleiber (1997) as a guide to understanding the process, "This process, by which children acquire motives, attitudes, values, and skills that affect their leisure choices, behavior and experiences throughout their lives, is referred to as socialization into leisure." (225-226). However, this study only interviewed individuals at least 18 years of age, not children, and most sociologists consider socialization to be a lifelong process. 
The differences between socialization into and socialization through an activity can be murky at times and not distinct. For the purposes of this study, it is important to keep the distinction in mind: socialization into esports involves the ways that a person is brought into the community, both how they find the community and what they are taught to become a member of the community. Then after they are considered a member of the community socialization through the activity begins. This extends to what a person is taught by their participation, both directly and indirectly about both the social world of the activity and life beyond. Using this study as an example: if an interviewee expressed that they found esports from scrolling through videos on YouTube and watching them, that is socialization into. If they then want to be a part of the community and go to tournaments and learn what is expected of them during participation and the ways that people are involved that is also socialization into. Lastly, socialization through then occurs when participation imparts certain values, customs, and actions onto the participants. These are not limited to values, customs, and actions inside the game but outside it. For example, if competing instills in a person a dedicated work ethic this would be considered socialization through for the purposes of this study.

When considering socialization into and through participation it is important to consider the performance ethic as well. The performance ethic is the concept that one's performance in a particular activity is measured and that performance impacts the quality of the experience (Coakley 2015:88). In leisure-based esports, this is particularly interesting, as for some players it may be true that their performance impacts their overall enjoyment while for others it might not be. The performance ethic pushes participants to constantly improve which pushes innovation within the in-group, but the performance 
ethic can also result in over-conformity (Hughes and Coakley 1991). Over-conformity can lead to negative aspects of socialization and the ignorance of harmful effects or outcomes of participation, or even the deliberate seeking out of the harmful effects or outcomes (Hughes and Coakley 1991).

In addition to how individuals are socialized into and through participation in leisure-based esports, this study analyzed participation regarding how individuals become more deeply involved over time. Specifically, Recreation Specialization Theory (RST) (Bryan 1977, 2000) guided the analysis of how participants developed behaviors, attitudes, and preferences based upon the understanding of Bryan's work by Scott \& Shafer (2001). RST is most commonly used to analyze outdoor activities, "The vast majority of studies have been oriented toward traditional outdoor recreation activities like boating, hiking, camping and the wildlife-based activities of birding, fishing and hunting. In at least one case, the specialization framework has been used to explore variation among participants in an activity, in this case contract bridge, that typically takes place inside." (Scott \& Shafer 2001:320). However, the concepts within the theory can be applied to any leisure or recreational activity as shown by Scott and Shafer (2001), "Bryan, however, regarded recreational specialization as more than just a variable that measured intensity of involvement - he believed specialization was fundamentally a developmental process whereby people progressed to higher stages of involvement the longer they participated in a leisure activity." (320).

This study used the orienting theory of RST as a developmental process guided by Scott \& Shafer (2001). In their work they state, "We propose that the progression can be understood in terms of (a) a focusing of behavior, (b) the acquiring of skills and 
knowledge, and (c) a tendency to become committed to the activity such that it becomes a central life interest" (2001:326). The purpose here is to identify if participants in leisurebased esports experience recreational specialization by finding some or all of the components of RST.

This study also used the Serious Leisure Perspective (SLP) as another orienting theory to guide the analysis of which category leisure-based esports participation is for participants. The categories of SLP are serious leisure, casual leisure, and project-based leisure (Stebbins 2001). Serious leisure has characteristics of 1) the desire to persevere at the activity; 2) availability of a leisure career; 3) need to put in effort to gain skill and knowledge; 4) usage of various benefits; 5) unique social world, values, and actions; 6) a personal and social identity (Stebbins 2001). Casual leisure is, “....defined as immediately, intrinsically rewarding, relatively short-lived pleasurable activity requiring little or no special training to enjoy it." (Stebbins 1997:326). Lastly, project-based leisure is, “...short-term, reasonably complicated, one-shot or occasional, though infrequent, creative undertaking carried out in free time, or time free of disagreeable obligation." (Stebbins 2015:xx). This study analyzed whether leisure-based esports was serious leisure and/or casual leisure for participants as it is unlikely that participation is projectbased leisure due to the time commitment and dedication required to be involved. Due to this decision to only analyze participation as serious and/or casual leisure; the analysis conducted was of the six characteristics of serious leisure, and if participation met all or most of the requirements it would be classified as serious leisure.

This study is also guided by the theoretical concept of social worlds. Social worlds are collectives of individuals coming together through discourse and idea-sharing 
over a shared activity or interest (Clarke and Star 2007). Social worlds can be spread across the Internet, a nation, a state, or a city. For this study, the social world analyzed is around a shared activity, leisure-based esports participation, and united by the Facebook group of a specific region; but a participant is not restricted to one esports social world and may inhabit more than one simultaneously. It is the social world that an individual is socialized into and through, that a participant may specialize within, and the activity that they are have experienced as serious or casual leisure. By analyzing socialization into, socialization through, specialization within, and SLP categorization of participation in this social world, this study is indirectly analyzing the social world. Connecting social worlds to SLP in the analysis, a person's level of involvement in the social world may be an indicator as to whether their participation was serious or casual leisure.

Socialization into and through esports may directly tie into RST as an individual is perhaps not only socialized into the activity but into a connection with the hobby and increased specialization (Taylor 2012). Once in the activity, the extent of socialization through the activity can be related to its category within the SLP. For example, if individuals view esports as serious leisure that is going to involve more socialization through participation as predicted by SLP (Stebbins 2001).

AJ Veal's (2016) Leisure Experience Perspective (LEP) was used as an orienting theory to guide the discussion of SLP. LEP is a combination of SLP and RST, one that combines it with other theories, most important to this study being the involvement of RST, to expand its uses. Veal's (2016) issues with SLP are summarized as “...the discrete activity typology and associated form-specific distinguishing qualities and costs/rewards are not a valid representation of the leisure experience domain.” (18). To 
correct this Veal (2016) proposed a "multi-paradigmatic cooperation" (18) that replaces the more rigid categories of SLP and places leisure experience onto a casual/serious continuum (13). Placement upon the continuum is decided by a participant's dedication and time put towards their participation, their involvement within their social world, and the completeness of their socialization within their social world.

\section{Objectives}

This study sought to understand the ways in which a person becomes involved in leisure-based esports participation, what this participation imparts upon an individual if participants become more specialized over time, and which category of SLP their participation falls under.

1. How are participants socialized into esports?

a. Which agents of socialization are most important?

b. What specific behaviors, norms, values, and/or thoughts are participants socialized into?

2. How are esports participants socialized through their involvement in esports?

a. What are the major agents of continued socialization?

b. How do participants' behaviors, attitudes, and commitments change by way of participation in esports?

3. Do participants become more specialized due to their involvement?

a. What are their motivations for entering participation when they started?

b. What are their motivations for participation today? 
c. What are their motivations for continuing to participate in the future?

4. Is leisure-based esports serious leisure and/or casual leisure for participants? 


\section{METHODOLOGY \& DATA ANALYSIS}

\section{Methodology}

The data were collected via semi-structured interviews by way of telephone calls conducted during September and October 2020 from a purposive sample. Interested parties responded to two recruiting posts on a Facebook group dedicated to a popular fighting game as esport. The requirements for the interviews were individuals who (1) were 18 years of age or older, and (2) participated in esports. Interviews ranged from seventeen to fifty-three minutes long, with an average of thirty-seven minutes. Immediately following the interview, the interviewees responded to a demographic questionnaire. The individuals interviewed were given pseudonyms and were all men, aged 18 to approximately 35 years old, and included several race and ethnic identifications, including Caucasian, Middle Eastern, Native American, Latino, Hispanic, and African American. See the Demographic Table in the appendices for a breakdown of the demographics reported.

This study analyzed individuals' levels of involvement in esports along the lines of motivations and influences within three time periods: the time when they were joining esports, currently participating in esports, and remaining in esports in the future. This study also analyzed whether individuals focused more on either the social themes of their involvement or the competitive themes during these three stages of their time in esports. This study was reviewed by the University of Louisville Institutional Review Board. 
Questions asked during interviews included how individuals found out about esports, what interested them about esports, what motivations and influences they had in joining esports, remaining in esports presently, and continuing in esports in the future. They were asked about any constraints they may have faced in esports, what they wanted to achieve, and how Covid-19 may have affected their involvement. Please see the Appendix: Interview Guide for the detailed questions that interviewees were asked. This study then produced a grounded theoretical analysis, as guided by Charmaz (2006).

The interviews were coded along with the categorized themes of esports they fell under. The process of analysis included line-by-line coding, following Charmaz's (2006) approach, which then grouped responses to the interview questions. The line-by-line codes were then focused, or grouped, further into the general categorization of their themes to understand the experience of socialization into and through. The focused codes were then categorized along the lines of whether they were connected to socialization into participation, socialization through participation, recreational specialization, and the category of serious leisure participation fell under.

The categories of themes that line-by-line codes were focused on are social, competitive, financial, physical, and mental themes. A theme of esports is any component of their involvement or interest in esports that then leads into socialization into, socialization through, specialization within, or the SLP categorization of leisure-based esports. Themes may be positive, negative, or neither and can be made of anything related to esports, even an experience that has occurred for them outside of esports but is influenced by or affected their participation. The categories are not always mutually exclusive as themes of participation may exist within two categories at once. In addition 
to this, there are uncategorizable themes of participation that existed outside of the neat boxes created by the categories, such as the process of hosting esports and the effects of aging on participation.

\section{Group Interactions Prior to the COVID-19 Pandemic}

Prior to the COVID-19 pandemic this was an in-person community which used Facebook as a way to communicate about tournaments, events, and connect at times they could not meet in person. The main focal point of interaction was the weekly tournaments held at a local retail shop. Once every week members would meet for the tournament and compete against one another. Each time the bracket would be set, and the competition would be had until a winner was crowned for that week. This weekly crowd could be the most involved in the community, or simply those who preferred the lower pressure environments of a weekly event. Roughly once a month a major event would happen. Major events would usually be held at a local retail shop or possibly a civic center if the event was large enough. Whether a weekly tournament, a major event, or a small hangout in-person participation in esports was a social gathering for participants as well. 


\section{FINDINGS}

\section{Findings}

The findings of this study are reported based upon whether they cover socialization into, socialization through, specialization within, or the SLP categorization of leisure-based esports. Findings then breakdown into smaller categories covering several themes of esports. These categories are social, competitive, financial, physical, and mental themes. An aspect of esports is any component of their involvement or interest in esports that then leads into socialization into, socialization through, specialization within, or the SLP categorization of leisure-based esports.

\section{Socialization into Leisure-Based Esports}

When looking at socialization into leisure-based esports one of the ways the themes are seen is in the agents of socialization. The listed major influences from interviewees were peers $(n=5)$ and streamers $(n=2)$. In addition to these, prior traditional sports experience, specific mentalities, and financial interests were additional ways they were socialized into esports. The performance ethic was a factor that aided in socialization into leisure-based esports.

Before an individual can be socialized into esports they must be introduced to it. While there were several reported ways that interviewees found esports, the most prominent was through their peers. Peers, for this study, refers to fellow participants in 
esports. They can be family as in the case of Devon who learned about esports from, "Uh, so I was first introduced to... [esports by] my brother specifically as a child...”. They may also be friends, as it was for Karl: "I was just ultimately playing video games with friends...they ended up introducing me to tournaments...". Some found esports through the Internet such as Frederick, “...I come across the Facebook group...”. While others found it through chance such as Allan, “...I actually work at [an organization] we actually held a lot of tournaments for that game."

No matter the entity that introduced individuals to esports, the major agents of being socialized into esports coalesced into just a few prominent options. The first of which, peers $(n=5)$, was stated by Caleb, "If I were to say the most influential or the first person that comes to my mind it would have to be another friend of mine." When asked how his brother brought him into esports, Devon responded with, "Uh...he was just, he would always ask me if I wanted to play with him and uh... sometimes I would say yes sometimes I would say no. But once I started learning the game and he started teaching me different things about the game that's what intrigued me the most." When asked about his friend, Caleb said, "But for me and him we were kind of the young, the young blood in the community that we both wanted to improve and get better at the game 'cause we just both have that drive to improve." In both instances, their social connection to their peers, their friend or brother, was combined with their performance ethic to socialize them into esports.

Imparting a performance ethic through a social connection is also seen in the next major agent of socialization, streamers. A streamer is an individual who livestreams their playing of a game online through a video service such as Twitch.tv. The streamer usually 
has a video camera on them as well and directly talks to the audience about the game or other topics while playing. The audience can respond through text chat and directly connect with the streamer. The roles that streamers play in games, and esports in particular, include mentor, entertainer, and public figure. While some in esports pay them little or no attention to streamers, for others they are respected figures in their communities. When asked about his biggest influence Frederick stated,

There have been lots of excellent figures, but if there had to be one that stands out to me the most. It's probably one person that I met on Twitch is a Twitch streamer and when I was playing online for fun, I would join his sessions. Pretty much get destroyed most of the time but he would always be there giving me feedback, he was like he was a positive [force] that I look up to in the community.

When specifically asked about the streamer, Frederick stated, “...it was like 'you're doing this too much' or 'you're not doing this enough you gotta start doing this' and keep really helping me to become a way better player than I probably would have been if I did not meet him." Once again, the social connection with the streamer worked off-of and fed the interviewee's performance ethic.

The performance ethic also serves as an agent itself to socialize into esports. In the case of George, when asked about his biggest influence when he started, he stated,

Um, so I kind of have a personal mentality about what I can get in about trying to get as far as I can in the bracket to obtain the best reference point I can. Because if I fall early in bracket, it'll always mean you know, like I'm worse than somebody I'm trying to find is very unspecific. So, I typically try to end up facing somebody that I, that's either ranked officially in a region or, you know, is very well regarded by the community in order to find some sort of like well-known reference point, uh, to validate my skill. 
George provides an example of the performance ethic at work; his mindset showcases that he values competition and comparing his skill to others. In the case of Allan when he was talking about having success in tournaments he said,

Results, you know, definitely make you feel better when performing. Just being able to play with new people and learn new things about the game itself which is honestly; if you aren't even placing well in the tournament, I would suggest you go. If you are trying to get better it is a really good learning experience, trying to compete in tournaments even if you win or lose.

In both instances the inverse of the social agent occurred; the agent of socialization for them is a competitive one, the performance ethic, but in the tournaments their ethic drives them towards, they are also being socialized into the social aspect of esports. Whereas when the agent of socialization is a social one, that agent socializes participants into the competitive themes of esports.

However, Gideon had a unique response within this sample to how he learned about esports. Gideon is a tournament host, rather than a player in the tournaments. A tournament host is the individual who organizes and runs the tournaments and events that players compete in. It is the host who organizes the space for play, collects the registration, communicates with the venue owners, sets up the tournament bracket, and makes sure the event runs smoothly. A single host may run a tournament by themselves or multiple hosts may work together for a single event. Without hosts tournaments do not occur, as such they are respected in the community. "I learned of esports from Korea," Gideon told me,

Back in StarCraft days I played RTSs and StarCraft is considered the very first esports for RTSs, real time strategy, and it was the first scene to really have professional esports and then of course there are fighters and things along those 
lines...YouTube had a channel where they would post their Korean broadcasts of the StarCraft games in the early days of YouTube.

Not only did Gideon learn of esports from the tournament hosts, via finding replays of their broadcasts, but it also influenced his agent of socialization. He stated, "My participation beyond literally casually playing really didn't start until I became an esports [tournament host]...So as far as influence goes, you know, I want to say it wasn't necessarily people that were influential it was more organizations..." For Gideon, it was neither a social nor competitive agent that drove him but one that does not fit as neatly into the boxes laid out,

Well, I loved watching it [esports]...And I knew I wasn't going to be, I didn't have what it takes as far as I have the drive to be professional. But I did want to try to make something. So, my excitement and enthusiasm for esports made me want to get involved. And since it wasn't going to be as a competitor, probably had to be on as [a tournament host], so allowing competitors to compete against one another.

Gideon was differemt because unlike other competitors his participation very quickly turned to hosting, whereas others like George became hosts much later in their participation. Other motivations that do not categorize cleanly came in the form of having prior experience in competition. For example, Frederick said, "I grew up in a competitive football background." Kevin said, "So throughout high school I played, and in middle school I played soccer and I did a lot of academic competitions and so there's always that competition in your brain and like your thoughts...". Others desired something that they found in esports such as Devon, "Um, looking for a new hobby. You know like uh, and outlet from the real world I guess." Or Caleb who said, "So, it's been a good escape...", and others like Kevin said, "Ah I guess I enjoy playing video games...." 
Lastly, for this uncategorizable group, there was Karl, who succinctly summarizes these reasons for being interested in esports and adds one more, "The competitive aspect of trying to put yourself better than others, the financial aspect and the just the social interaction with other people." In his statement Karl mentioned the financial aspect of esports participation; this aspect involves both the monetary commitment required to own the game and compete in tournaments but also the potential for monetary gains. Even at the leisure-based level prize money is won in tournaments. While a person's internal motivation is not exactly an agent of socialization, it influences the decision to join and participate.

Socialization through esports follows a similar approach as socialization into esports. Agents of socialization bring new participants into esports, but they also impart specific things upon the individuals involved. Those non-mutually exclusive agents once included both peers and streamers as mentors $(n=4)$ and hosting tournaments $(n=2)$ which are the same agents as to how someone is socialized into esports. In addition to those agents of socialization, power rankings $(\mathrm{n}=3)$, lists that rank players against each other based on skill come into play as a way participant are socialized through their participation, and the performance ethic aid in socialization through. Where this differs dramatically from socialization into esports is that socialization into participation focuses on bringing people into esports and showing what is expected of them from their participation while involved in the established social world. Socialization through esports participation however imparts thoughts, feelings, and actions onto the people involved for both within and outside of the established social world(s). 


\section{Socialization Through Leisure-Based Esports}

Just as an individual may be socialized into esports by peers, their continued connection socializes them during their participation as well. Several listed their friends and peers as their biggest influences for remaining in esports today. Caleb said it best when talking about his friends, stating, "I'd say they are a big part of why I want to still be in the community just to hang out with them. And by extension a lot of other members of the community. There's a bunch of people I've grown close friends with, and I'd say the social aspect of hanging out with people..." In a different social connection, streamers are agents of socialization through participation. For example, Frederick said, "Because, even to this day whenever I have a question about a matchup about a certain character, I always...I always ask him and he's quite knowledgeable about the game." On top of just being agents of socialization, the relationships formed during esports participation may specifically include a mentorship. In these quotes several benefits of participation are listed; including making friends, growing close to friends within the community, and usage of a mentor to continuously learn and improve. Not only are these agents of socialization through, but they are also benefits of and reinforcing socialization into participation.

Mentorship, in particular, is a benefit of socialization into and an agent of socialization through participation. A mentor could be anyone in the community, but for Caleb, it was a friend of his who was older and in the scene longer:

I'd say [he] being a mentor to me meant a lot to me, especially back then as it was someone who actually had like faith in me to do well in events and stuff like that. And it was for the first time I had a hobby that I was very interested in and really wanted to push myself to improve at and he was someone who was always willing 
to help me learn from how I played, how to improve [and] as a father figure to me in the community sense.

But for Frederick, it was the streamer who first introduced him to esports acting as his mentor: "He's always there to lend me information, feedback he's always there to kind of guide me as to what I'm supposed to do to get better as a player." Be it peers or streamers, the sentiment behind socialization through leisure-based esports participation is that the social connection and aspect of esports connects individuals and guides socialization. The agents guide socialization either by connecting with other participants or the direct act of mentorship which while it imparts game knowledge and skill is a major agent of socialization.

The process of hosting tournaments or esports events is an agent of socialization through participation as well. George started hosting a few years after he first started competing. When asked why he stated, "So I was trying to build a community around the [physical location of the tournament] that [we were] already having a tournament at. And I think that worked really well. I ended up making a lot of tournament organizer friends in the process." Even when hosting is the agent of socialization for George a social connection, making friends who also host, immediately jumped to his mind. Gideon however had a different outlook,

To a certain extent, obviously, you can't always be yourself, whenever you're running events, be your true self...A lot of a lot of people come to our events, even if they're not, they're playing, like they're entering the tournament. But a lot of [people] come into this, because they want to hang out with a lot of friends, the community that they see there for it. And I don't have as much of a chance to do as few people in the community that I'm open to that I'm friends with and stuff like that. But they have to largely see that outside of the [tournament] that I'm hosting, because I can't completely act as myself at the [tournament] that I'm hosting. 
For Gideon, hosting is focused directly on the effort of running a good event, while for George the social connections he made were front and center; but both of them are being socialized by the process of hosting and what they desire out of it. George stating that he wanted to build a community showed that his mind is on socializing whereas Gideon stated he could not always be himself, and because of that there is a distinction between him and other participants. Hosting tournaments, at least in this sample, is an agent of socialization unlike others in esports because it relied on the participants uncovering what they were being socialized into on their own; and they even came to different conclusions.

Socialization through leisure-based participation separates itself from socialization into esports by imparting thoughts, feelings, and actions upon individuals beyond just bringing them into the hobby. These themes that they are socialized into are best broken down to social, competitive, financial, physical, and mental themes. In particular, the social themes individuals are socialized into are firstly a community that emphasizes fun. As seen in the case of Jace when talking about how friends he made in esports

...would travel out of state to tournaments, like I would drive...And, were interested in competitive fighting games so a few of them would hop in the car...there were such a special bond that you had and you could just talk about the game the entire ride up, but it was fine. But oftentimes it went beyond that. And I was redefining what friendship was at the time.

For Jace, the community of fun is a focus on travel and friendship, and in this thinking, he was not alone. Frederick in particular stated this when asked about being taught to make friends, "Yeah, form of bonds 'cuz even when they are technically being 
competitive at those tournaments, I am always still trying to talk to people I'm always just trying to support them. As they play live because, those kinds of bonds go a long way..." The statements from Jace and Frederick both show that they value the formation of friendships in their participation.

Participants were not exclusively socialized into making social connections via their participation. There were also competitive themes they are taught, which is where the performance ethic comes into play, such as with Devon, who told me, "I'm just wanting to get better, I would like to be [power] ranked...". Devon directly pointed out the power rankings which are an agent of socialization through, and what they socialize participants into is the performance ethic. Allan, when asked about what drives him to keep playing and improve, stated, “Obviously, nobody's pushing me, it's just the enjoyment of the game." This quote is steeped in the performance ethic of leisure-based esports when Allan mentioned that no one is pushing him to compete and improve. For Allan, it is not about others driving him to improve but his love of the game and desire to be better, this is the performance ethic at work. Both of these quotes show two people connecting with the performance ethic and wanting to improve. Then, there is Kevin, who connected his participation in esports to his life as a whole when he stated, "...like I most of what I've done is like competitive throughout my life and so I guess this [esports] ties in the competitiveness with enjoying myself and what I'm doing...". In this quote, Kevin has shown that not only does the performance ethic push him to improve in esports, but it also helped his socialization into leisure-based esports.

How participants interacted and prepared for tournaments relates to the performance ethic. In particular, Allan listed performing well in them as a motivating 
factor, "...just so happens that I must be prepared and being able to win and you know, show out and do these things in these tournaments it's just satisfying to some extent you know." This quote shows his performance ethic pushing him to show his skill in tournaments. In contrast to Allan, for Percy certain competitions are a place to relax, "There's also [tournaments] at the bar that I go to, I used to go very early, and it was very nice to get involved with the older guys more around my age. And that was more of a chill, relaxed, not so competitive scene, which is good." This quote is a very different style of the performance ethic, rather than performing in skill it is performing according to the social conformity of the less competitive environment. Lastly, in the case of Devon, tournaments are a means to an end for him as he explained when talking about his skilled friends in the scene, "I want to pass them honestly, in skills and you know results and rankings and all that good stuff." The tournaments are where he achieves those results and what are used to calculate the rankings he spoke about and his performance ethic drives this desire to do so. Those rankings are specifically power rankings that rank the best players in an area, that area could be a city, a state, national, or even international. The performance ethic imparts very different ideas for individuals; it can be a motivating factor, such as how it was Allan, a connection to a non-competitive environment, such as bar tournaments for Percy, or a place to test skills, as was the case for Devon.

In addition to the themes previously covered, Jace stated, "I'll pass up going to tournaments, if one, there's not enough money involved [or] I don't think the incentive is high enough." With this quote, he showed that he has been socialized into consideration of money via his participation. Jace also expressed a different sentiment, one that was 
echoed by other interviewees, when he stated, "For now, the short term what I want to focus on is bettering myself outside of [esports]...". Jace, in particular, said, "I've recently lost [a lot of weight]..." to which he attributed the dedication and work ethic he had received from his participation in esports as a reason that he was able to stay on the path of a healthier lifestyle that led to his weight loss. Percy summarized being involved in esports with, "It has improved me as a person." echoing the notion that the desire to better oneself has come from participation in esports, be it monetary reasons or selfimprovement outside of the game. Lastly, when asked about how he feels during play Frederick stated, 'I'll start to shake a little, I'll start to sweat...gamers have this thing when they're playing in a competitive matchup they won't lean back, they're locked into the game." In this quote Frederick is describing the physical affects of play on his body and he is also describing a state of flow. Flow is summarized as a state in which a person is enjoying their activity or experience so much that other things cease to matter in the moment (Csikszentmihalyi 1990). Being 'locked into the game' and feeling physical effects of play shows that Frederick feels flow when playing. Other interviewees did not directly express similar effects of play, but it is likely they experience flow in some capacity during play.

\section{Specialization Within Leisure-Based Esports}

Specialization within esports may come in various forms. Using the components of RST as previously designated by Scott \& Shafer (2001), the journeys of several individuals can be followed. While it would be preferable to find every component of RST, finding only some of the components can still suggest recreational specialization. In addition to that, it is important to note that not everyone may follow the same path of 
specialization. Instead, there may be different forms of specialization within esports participation.

In order to find the first component, a focusing of behavior, it is important to follow the journeys of individuals to identify which of the two main themes the individuals' focus was on when they started, to where it was at the time of the interview, and then to where they expect it to go in the future. By following this journey specialization may be found in their focus shifting. Firstly George, who when asked about how his mindset today differs from when it began stated,

I'd say it is a comparison point. When I started, the main difference I'd say between when I started competing and how I compete now; is that when I started competing, I mainly just wanted to go as far as a I could in bracket. Now it's not more about how far [I'm] going in bracket, but who I can manage to fight against how I fight against them.

George sought to prove himself at the start and go as far in tournaments as he could. This then turned into wanting to beat the better players and prove himself against them. When asked about the future he stated, "Oh, so my reasons for continuing to produce in tournaments, uh, like I said earlier, still just reminding myself of a benchmark for um, managing to, you know, see all how good I've gotten or if I've gone down in skill, you know things like that." But also, he mentioned that he started hosting online tournaments and stated a goal of his, "So, like having a tournament with like [hundred or more] people and it being international, finally meet all those people that play in my tournament series would be fantastic for me, that is like my greatest dream..." This journey of specialization focused on competition and the performance ethic, first wanting to prove himself by going far in the bracket but then by beating the best players; then it 
continues with him becoming a tournament host himself; and lastly he provided the avenues for other people to engage in the activities he previously had.

Percy put forth a similar journey. When asked about what held his interest when he was starting, he stated "And I just wanted to win. And I wanted to win, and I wanted win. I wanted to win. That's my driving thought. That's kind of my driving thought to this day, but I'm much older." However, when expanding upon what keeps him in esports today he mentioned 'Um, I like watching the local scene develop. So, like [uses player's name] and I met him when he was 14, but it was nice to watch him kind of grow into a leadership role." This statement from Percy shows that he shifted towards more social themes after starting with a more competitive mindset. Specifically, Percy went from purely being a player to then being a player and a mentor.

When asked about the future Percy stated, "For me...probably just trying to get into coaching. Playing stuff here and there, helping run events, continue to be involved." This quote showcases an even deeper shift towards the more social side of esports with Percy indicating that he may be playing less and start helping to host and run events. Both George and Percy expressed a shift from a more competitive mindset early on to a more socially focused mindset later. The added leadership and responsibility Percy desires to have as a coach suggests specialization.

On the opposite side of Percy, who started by focusing on the competitive aspect to then shift towards the social aspect, would be Allan. When asked about his mindset when starting Allan stated, "Just being able to play with new people and learn new things about the game itself..." as his biggest motivation early on. This quote shows his focus on both the social and competitive side of the game but purely through a social agent of 
meeting new people. When talking about his current participation he stated, "I would say the biggest thing that keeps me going in these tournaments is because generally I play the worst character in the game...I had a little gang back called [group name] and in my group, I was one of the top brass. [Everyone] either mained or sided [character name] in their arsenal." With this quote, Allan is showing a slight shift towards the competitive and now using his character as a vehicle for socialization. Lastly, when asked about his future he stated, "Going towards a better ranking and being able to compete a lot better with these people who have been playing for years." With this quote, Allan is showing an even further shift towards the competitive side. When looking upon the journey of Allan, he started from a social agent then shifted his focus towards the competitive themes and saw his future shifting even deeper towards the competitive themes, we see a journey that is different from the journeys of Percy and George. Even though it is different for all three, each journey showcased a narrowing of behavior.

The second component of RST is "(b) the acquiring of skills and knowledge," (Scott \& Shafer 2001:326). This is exemplified by the abundance of mentorship ( $\mathrm{n}=6$ ) found by this study. Allan stated, "But I managed to get one of my coworkers in the game to bring them in and I'm teaching him how to play ever since the shutdown initially started." Mentorship in esports is passing along the knowledge. As mentioned previously Frederick has a mentor, and said, "...he's always there to kind of guide me as to what I'm supposed to do to get better as a player." With this quote, the direct acquirement of skills from mentorship is seen. Going along with the acquirement of skills is the acquirement of knowledge; this knowledge can be about more than just esports as was the case of George, who stated, 
Um, let's see what's the best way to phrase this, um, before I started playing in esports, um, I really didn't think that, uh, that highly of fans of sports... So I was just like 'no y'all are wasting your time here. I don't think there's anything special here, but when I started playing esports. I started discovering that, um, you know, people have a real emotional connection to the teams and people you cheer for in these games...

This instance was personal knowledge and understanding gained by George, rather than something purely pertaining to esports. However, everything participants are socialized into and through about esports as well can be considered the knowledge and skills they have gained from participation in leisure-based esports.

The last component of specialization "(c) a tendency to become committed to the activity such that it becomes a central life interest" (326) is best seen in their statements about not being able to compete in in-person tournaments during the COVID-19 pandemic $(n=6)$. Jace stated, "This is the longest I have never played [the game] in the 12 years I have been a part of the scene." For Devon he stated, "So, I'm not able to actually, you know, bond with my, my friends that I used to at weeklies and it's a dampener for sure... and I feel like I learned most when I was playing in person with friends rather than playing online..." Karl stated, "Because if you're not communicating with the person on the other side it's like playing with a robot, you don't get that socialization, [and] you get frustrated because you're not joking with the other person while you're playing." All three of them were showing how important in-person tournaments were for them by missing it as the pandemic has taken it away. Specifically, Karl was missing the direct communication offered by in-person events. People can communicate using third party voice apps or technology but the game itself has no voice communication capabilities built in. No one in the sample reported making a living primarily from esports. For all of 
them, it was a dedicated hobby. Whether or not this can fulfill the third requirement is best seen if it fulfills the qualifications of serious leisure. If it is serious leisure it fulfills being a significant part of the participants' lives.

\section{SLP Categorization of Participation in Leisure-Based Esports}

Firstly, 1) the desire to persevere at the activity (Stebbins 2001) is found easily when asked about their future in esports. For example, Devon stated "But, I do see a bright future. I think I have the capabilities to achieve my goals I discussed as far as getting on the power rankings. So that's uh, I feel like that those will, you know, come to fruition in time." Or consider Percy, who stated, "For me...probably just trying to get into coaching. Playing stuff here and there, helping run events, continue to be involved." Caleb stated, "In my head right now, I want to be in for as long as I can, it's been a big part of my life and there's not really much motivation for me to quit, other than I guess age, when it comes time where I just can't perform well.” Lastly, Frederick stated,

I am happy to announce that people that run the scene in [city name] they've considered me [in the power rankings]...It definitely convinced me that maybe I can serve the contender for top [spots] in [city name] or [state name]...eventually if I keep practicing.

In each of these responses a desire to continue, or persevere, with the activity is shown, but another way to see this desire is when looking at the constraints that participants overcame within their participation.

The most common constraint faced by participants was school life $(n=4)$. Frederick, for example, not only talked about school being a constraint for himself but for others as well when he said, "I'm not trying to generalize all esports players as this 
category but, a vast majority of them are in college or in high school. They are students and school just comes first." Even though school did come first for Frederick, and the other students from this sample, it was a constraint on their involvement but one that did not stop them entirely; they instead did what they must for their education and then participated in esports. Percy also dealt with constraints, but different from school, he stated three in particular, "Old age, I can't practice as much as I used to...Also interacting in tournament form pushes my anxiety." This quote shows three constraints that Percy overcame to continue his participation. Old age was not merely that he is older than before but the responsibility that came along with moving through the stages of life. Percy had more responsibilities in his life than in years past, as such he could not practice as much as he used to, and for him interacting in tournaments with others was taxing on him; yet the constraints did not dampen his resolve or determination to participate in esports. At the time of interviews for this study, every participant in esports was dealing with the same constraint, however, COVID-19.

The COVID-19 pandemic drastically changed the way esports were played for the entirety of 2020. “...it's taken away, like, in person events for games...” Kevin told me about the pandemic. Caleb stated, "I'm kind of just taking a step back from competition, like play for fun online and to improve...". Playing online for fun during the pandemic was something several other interviewees mentioned as well $(n=6)$. They were actively still involved in esports despite the pandemic, as were others like Allan with his role as a mentor to his coworker. George in particular was heavily involved, as during the pandemic he focused on hosting online tournaments. He stated, "The whole point of that tournament series is to provide a place where people from my in-person community 
could go to play online tournaments.". Whether the constraint came in the form of school, multiple facets of life, or the pandemic they were overcome, and the desire to persevere in esports was clearly evidenced by the interviewees.

The second requirement is 2) availability of a leisure career (Stebbins 2001). For the purposes of this study, a leisure career is a set of definable tasks and activities that an individual does over the course of a long period of time to fulfill a leisure role or activity. This working definition is based on Stebbins's (2015) broader definition. This concept is expressed best by Gideon and George. When talking about one of his motivations for continuing to host, he mentioned how competitors perceived him: "Gamers are very excited; maybe they've heard of [the group] even if they haven't participated." George mentioned that "When I see people having fun at my tournaments, I'm like 'I can do this successfully'. And this community that I built is still having fun, doing what I've been doing for them." In these two interviewees, there was a difference from most. Whereas most participants took up the leisure career of a competitor, focused on personal performance and power rankings, George and Gideon focused on hosting events; their participation was beyond playing. Not only does leisure-based esports appear to have a leisure career, it may have at least two; the career of a competitor in events and tournaments and the career of a tournament host. These leisure careers were not mutually exclusive, as George both competes in some tournaments and hosts others.

The third requirement is 3) need to put in effort to gain skill and knowledge (Stebbins 2001). Before one can improve, they first have to understand what their skill level is.; to understand one's own skill level tournament results and power rankings exist to classify participants. Thus, using those as a goal post an individual can train by 
themselves or find a mentor to help them climb the rankings or get better in general. This training requires time and dedication and is not something every participant can easily do on their own, thus many seek out mentors. For example, when Devon was first starting, he stated about his mentor, "started teaching me from the beginning, high-level tactics and high-level things that, you know, most beginning players don't learn for a long time." It is his usage of 'don't learn for a long time' that directly shows the effort and time that would be required of a player to learn these techniques. He is bypassing the time requirement by using a mentor, but not the effort required to learn the techniques. Participants can be extremely dedicated, even to the extent of hurting themselves, such as Percy, who talked about his former practice routine, "I would sit hunched over with my wrist literally pushed into the ground for hours and wouldn't think anything of it...I can't practice for long, eight-hour sessions, that I used to, 'cuz I used to practice for 8-10 hours at a time." The reason why Percy cannot practice for 8-10 hours anymore is that those long practice sessions he used to do have now led to him having [a repetitive motion condition]. The effort and dedication he put into his training led to a physical issue he now deals with. Effort is required to gain skill and knowledge in esports but most interesting to this study were the ways that participants were helped in the gaining of that skill and knowledge, such as by finding a mentor such as Devon, or the effects of such efforts, such as the [a repetitive motion condition] now dealt with by Percy.

The fourth requirement 4) usage of various benefits (Stebbins 2001), but specifically for leisure-based esports, it is both about the usage of various benefits and the acquirement of such benefits. As stated by Devon, "Like a sense of accomplishment...that's definitely a sense of accomplishment and it's just rewarding in 
general whenever you uh, you know, overcome the obstacles." For him, it was a sense of accomplishment. For others though, the benefit of mentorship was often seen, such as with Caleb when discussing his friend and mentor:

And it was for the first time I had a hobby that I was very interested in and really wanted to push myself to improve at and he was someone who was always willing to help me learn from how I played, how to improve [and] as a father figure to me in the community sense.

For Caleb, the benefit of mentorship was so important to him that he listed the friend as a 'father figure' within the community, showing a deep bond between the two. Another method that shows the usage of benefits is the creation of a team, Allan said, "...I had a little gang back called [group name] and in my group, I was one of the top brass." With this quote, Allan showcased the same benefit earned by participation as Caleb was, friendship. However, Allan is not using friendship to have a mentor, but to instead form a team. His team was then a way that he could become closer to his friends and being one of the top members of the group allowed him to be a socialization agent for others.

The fifth requirement 5) unique social world, values, and actions is abundantly clear. This is seen in the Facebook group used to ask for volunteers for this study. The Facebook group tied the participants together into a singular in-group, a specific social world that is even unique from other collections of fighting game players and esports participants. Within that other evidence was found, such as Allan who used the word "mained," meaning which character a player focuses on and uses as their main character in the game. The tournament scene itself is a unique environment where the social world is seen. Caleb, like Allan, created a group and when discussing the group portrayed their 
values and actions, Caleb said, "So, I think the things that we do in [group name] is we have a [group] chat and we talk all the time either, either about game or about the game or just about life in general." The quick example of tournaments and a specific set of slang showcase the social world, the value of communication and friendship shown through the constant chat about the game and life in general, as well as the action of forming or joining a team. These are just a few examples of the fifth requirement being fulfilled.

The last and sixth requirement for classification as serious leisure is that it contains 6) a personal and social identity (Stebbins 2001). Personal identity is hard to directly identify for these interviewees but nine of ten did use it to improve themselves as people. "It's a big confidence boost honestly," stated Allan. That personal improvement, be it building confidence or physical health as stated by Percy about his weight loss, is a way of showing a personal identity built upon the foundation of esports participation. Social identity is much easier to find; for example, Frederick stated that he was shy before he started competing. Then later on, "[at] tournaments more faces started recognized more people started recognizing me and it always feels good having people recognize me by my gamertag and knowing who I was." This quote demonstrates the social identity that was found within esports, a personal connection with others based upon participation. The social connection made included social identity labels of competitor, mentor, and tournament host; all of this together shows that a social identity was certainly formed. 


\section{DISCUSSION}

\section{Discussion}

This study used the idea of non-professional esports participation being leisurebased. As explained in the introduction, however, this is not a definitive remark on the matter, but a choice made solely for this study. Questions remain about its placement as either leisure or recreation, in particular, if esports could be considered recreational sports. A recreational sport is an enjoyable activity that provides the potential for acquirement of skills and knowledge, maintenance of physical health, and mental health benefits (Gagea et al. 2010:55). As seen in this study esports provides the potential to acquire skills and knowledge and mental health benefits, but has questions surrounding physical health. Esports does not directly provide a benefit to physical health and too much video gaming, regardless of esports or not, can have detrimental effects on health if a participant over-conforms to the performance ethic (WHO 2018). Over-conformity to the performance ethic of esports would be not healthy, and thus not recreational, but it would still be leisure for those who over-conform. The stance of this scholar and study is that non-professional esports is not recreational sport due to the less than substantial physicality directly involved in esports.

The performance ethic is very interesting in connection to esports. It was found to play a role in both socialization into and through; beyond that, it might play a role in specialization and the question of SLP categorization. It also connects to leisure versus 
recreation and where esports fits. To care about performance is closer to recreation rather than leisure as competitiveness within reason is seen as a good quality, thus something to be reinforced by recreation, but not necessary in leisure. The stance chosen in this study was to include as many perspectives as possible and not invalidate them. For some individuals, those who care very much about tournament results and power rankings, esports could be recreation. While others, who do not care about results or rankings, can view their participation as leisure. Both stances can exist simultaneously. In that regard, it would be best the view the whole as leisure but allow for recreation on an individual or group basis.

Both socialization into and through used agents primarily of two themes, social and competitive. Both the social and competitive themes of esports are equally prominent, to put this into a word there is cohesion between the themes. There is cohesion when an individual is joining esports and in the ways they are socialized through participation. When an individual brought a performance ethic, they were taught the social themes of the game during socialization into participation. When an individual found esports through a social connection, however, they were then taught about the competitive themes of esports during socialization into participation. The dual focus, the cohesion, was found to continue during socialization through participation as well. Participants were socialized through both social and competitive agents and taught themes of esports and the wider world. This also involved a process of self-actualization that occurred within the individual. Seen in the cases where participants used the drive and ethic, they harnessed in participation to better their lives. The other themes: mental, 
physical, and financial were in the mix but were certainly beneath social and competitive in terms of importance.

RST in leisure-based esports participation is not a clear-cut case of increasing specialization. George started out focusing on the competitive aspect when beginning, then balancing the competitive and the social themes, and now that he was a tournament host, predicted a deeper shift towards the social themes in the future. This was a decision he made out of his connection to the social themes of esports. The path of Percy started with him focused solely on the competitive side of participation. This then shifted towards a balance of the competitive side and the social side of participation and then ended with him forecasting a focus on the social side of participation. Allan was different still. He started out focusing on the social and competitive sides of participation, slightly shifted towards the competitive themes today and predicted a deeper shift in the future. What was shown was the acquirement of skills as well as the individuals being committed to the activity, as well as adoption of leadership roles and responsibility within the social world(s). This study did not find evidence of a singular pathway of specialization in leisure-based esports but evidence of varying pathways of specialization within the personal accounts of George, Percy, and Allan. Because of the varying accounts, there is modest evidence to suggest that specialization does occur within leisure-based esports participation.

A lot about specialization was left untouched by this study. For example, entering into esports at all is a process of specialization itself. First, an individual must choose playing video games as leisure, then, in some order, they must choose competitive gaming, a genre of games, and a specific game to compete in. On top of that, an entire 
pathway of specialization was intentionally ignored by this study, the path that takes a leisure-based participant into a professional. Thus, when this study found specialization it was finding specialization within an already specialized corner of video games. All of this is wrapped within a unique set of layered social worlds.

This study did not dive deeply into the social world that it was analyzing, but there is a multilayered system at work. Choosing to be a gamer, one inhabits a social world of a general fandom, like a moviegoer or book enthusiast, but within that is a divide between casual gamers, hardcore gamers, and competitive gamers. In short, most people are casual gamers and enjoy their games as a hobby and gaming is often casual leisure for them; hardcore gamers make gaming their main hobby and for them, it was often serious leisure, and competitive gamers are esports players or play competitive games that are not esports, and for them, gaming could be casual and/or serious. One individual could be any of the three depending on their involvement in the specific game they are playing. After that divide is the specific genre of games one plays, again a single person can play any number of genres, but they exist in their own social worlds. Next would be the specific series, and lastly the specific game. Social worlds can also be created around enjoying the work of a specific video game company regardless of any other criteria, among other things. All of these social worlds are not mutually exclusive and intermingle and fluctuate, but distinctions can be made. Players of a real-time strategy game may not act, look, or think like players of a fighting game and as such, they inhabit different social worlds. To reiterate from the top down: gaming as a whole, casual/hardcore/competitive, genre, franchise, and then game. 
Casual/hardcore/competitive though might be better set aside from this classification and seen as forms of specialization instead.

It is within the social world that participants found the community bond they desired. Sharing the activity and interest with others led to the formation of bonds, accruement of benefits, and betterment of self. These bonds, benefits, and selfimprovement were not limited to within the social world. As many interviewees mentioned the confidence, they gained from esports participation helped them in their lives in gaining jobs and academically. Mentorship directly gave them a personal connection and bond to another that many wanted to recreate with others in the community or by bringing someone outside of esports into it. Something not analyzed by this study was the commodification present in leisure-based esports and the general openness to new participants. Many interviewees expressed that they felt the community was very welcoming, but if the sample had included women this could have been different. It is likely that commodification and general openness to new participants varies based upon the specific social world of the in-group, as such this population may differ to other in-groups.

Esports as a whole has become more culturally accepted and mainstream. This is seen in the cultural impact on young people, such as the interviewees who see their participation as an important part of their lives and the 500+ individuals in the Facebook group. With its rise in prominence esports have become more diverse in their demographic makeup. However, it is still largely an activity partaken by men. It is important to note that fighting games are a small and less popular section of esports, as such they may be more insulated and less diverse than esports as a whole. Another reason 
for this may be the prevalence of sexual harassment and cyberbullying faced by women in gaming and esports. In 2020, over 70 people in the gaming industry came forth with their experiences of sexual harassment, sexual assault, and gender-based discrimination within the gaming and esports industries (Lorenz \& Browning 2020). Brehm (2013) directly explored the role of gender in the massively multiplayer online role-playing game World of Warcraft which is not an esport but the findings of the study may be transferable to esports participation.

The last question of the study was if participation was serious leisure for those involved in leisure-based esports. The first five requirements of serious leisure were easily fulfilled. The last, however, was tentatively fulfilled when considering social identity; as ample evidence of social identity was found, but little direct evidence of personal identity was found. Even so, this study puts forth that fulfilling a social identity, at least to their fellow participants, fulfills the final requirement and states that for these interviewees their participation was serious leisure.

Even though all of the participants in this study fall under the serious leisure classification, there is variability in terms of focusing behavior, skills, knowledge, and esports as a focal point of their life. Veal's (2016) LEP, combines several components of SLP and supporting theories and presents seriousness as a continuum rather than a categorization. Veal (2016) also suggests that increasing specialization may occur within the continuum, thus uniting SLP with RST as well. Placing the participants of this study on a continuum; those that are more heavily involved in the community, such as the tournament hosts and those who had taken up leadership roles or responsibilities within the community, are more serious. However, newer participants are likely to place as more 
casual or someone who does not involve themselves as much in the community components of leisure-based esports participation, such as Jace. Rather than a continuum of casual leisure to serious leisure, this study proposes a spectrum within serious leisure placing esports participants on the side of the social themes or the competitive themes of involvement. For example, Allan, whose focus was on helping his coworker enter the scene, was heavy on the social themes side; Jace, whose focus was on competing at the highest level he possibly can, was firmly on the competitive themes side; and George, whose focus was on hosting tournaments, was in the middle.

In conclusion, for socialization into esports; when a participant found esports through a competitive agent they were socialized into the social themes of participation and when a participant found esports through a social agent they were socialized into the competitive themes of participation. Both of the social and competitive components of participation were equally valued and as such the prospective participant was socialized on the component that they did not come to esports already with. After that occurred socialization through esports participation began. This expanded upon socialization into by introducing specific thoughts, feelings, and actions into the social and competitive themes of participation. It is not just that a participant connects with others, instead, they stay after tournaments and play friendly matches with other participants as Allan mentioned. It is not just that they play to win, but they compete in weekly tournaments as often as possible and try to win there. However, socialization through participation expanded into other avenues of life as well. Participation can bring about financial rewards for doing well in tournaments, and it commonly brought about mentality changes 
for those in this study. They developed discipline, which for Percy also resulted in physical changes in the case of his weight loss.

There was specialization within this sample, but it was not linear and not the same for everyone, but it always involved a narrowing of behavior. In general, it started with a participant being more focused on the social themes of participation, then evenly split between the social and competitive themes, and then being more focused on the competitive themes as their time as a competitor was winding down. However, once out of active participation the social involvement might become more important, as Percy noted he wanted to get into coaching, taking on a leadership role, in the future, and for those who host tournaments, they existed outside of this paradigm entirely. As for their placement on SLP this sample categorizes as serious leisure. However, for each of them, their involvement varied. When considered as a continuum it still did not cover the variance. A tournament host's involvement, like George, was very different from someone who was focused on competing at the highest level possible, like Jace, or someone who was focused on bringing his friends into the community, like Allan. Where they all connected were the intersecting lines and cohesion of social and competitive themes.

The impact of the loss of in-person events due to the COVID-19 pandemic cannot be overstated for this community. As previously mentioned all ten interviewees expressed a dislike of participating in online play (versus in-person play) and several stopped playing the game as much as they used to because of it. For them in-person participation was a vital component of participation in general. Allan for example, shifted his focus from competitions towards mentoring his colleague because he did not enjoy the online 
experience. The interviewees in this study sought out in-person participation and others like them do as well, the benefits they received centered around the social bonds and connections made, and their desire to continue involved social ties as well.

\section{The Value of This Study}

The value of the study is in its exploratory nature. Prior literature to this study focused on professional esports participation, this is one of the first studies looking at leisure-based esports participation. This study provides the groundwork for future research and can be used as the basis/inspiration for a multitude of studies covering a range of topics in leisure-based esports, including deeper dives into socialization into and through leisure-based esports participation, recreational specialization of participants, and its categorization within SLP. This preliminary study provides a great deal of value and can be the start of a new section of esports studies in the sociology of leisure.

This study is only the first step towards understanding leisure-based esports participation. This study only provides an understanding of a small sample of a community but the conclusions it does provide can be the basis for future studies of local level esports, leisure-based esports, esports as a whole, or other locally based leisure activities. 


\section{LIMITATIONS \& FUTURE RESEARCH}

\section{Limitations}

The limitations faced by this study came in a few forms. Most notably, only ten interviewees participated in the study from more than 500 possible members. However, patterns and themes still emerged within the data to show its authenticity. While the low sample size might not be able to identify outliers within responses the exploratory nature of the study views all responses as valid. Due to the decision to find interviewees on a Facebook group the purposive sample was made up mostly of people from that area and specifically one in-group (the Facebook group). Even so, the responses from this group were not homogeneous and included a wide range of data.

All interviewees were men, most were white, and age ranged from 18 to approximately 35 . This could not be helped as these were the only interviewees who responded to the posts. From prior research, it is also known that young white males are the predominant demographic when it comes to esports participation so with a low sample size this was a likely outcome.

The biggest limitation was Covid-19 and the restrictions put in place because of it. Instead of being able to set up interviews in person, through observations, and getting to meet the potential interviewees beforehand, two posts about the study were the only contact point interviewees had to understand the study and what their involvement was benefitting. Even so, ten interviewees still provided rich data. These ten came from 
various facets of a popular fighting game's participation and their responses ranged just as much.

Being restricted to telephone interviews did impact the richness of data collected. Due to not being able to see the interviewee during the interview, physical responses to questions could not be seen. Those might have led to follow-up questions which could have provided new information. The data could be quite different if another sample from this group would be analyzed. The data could also be quite different if another of the game's groups from a different geographic region was analyzed, or a group based around a different game. Even more so the data could be very different if an entire nation of players of analyzed or an international collective. Many factors shaped this data and by changing either the game, the location of participants, or both the data could come out very differently.

This study intended to analyze if participants in leisure-based esports based part of their personal identity on their participation. However, the questions asked did not delve into the topic well enough to gauge that in any meaningful way, or the interviewees were not sure how to answer in a way that covered this objective. While it was important to this sample of participants, this study cannot claim that they formulated their personal identities based on, or around, their participation.

\section{Future Research}

Future research should endeavor to analyze several components of this study in further detail. Socialization into esports, socialization through esports, recreational specialization within esports, and its classification within SLP all should be analyzed 
further, using different locally based groups or wider populations. The types of responses provided by other samples and populations could be quite different.

In addition to this, however, several areas this study could not explore should be studied. In particular, future research should analyze whether or not participants base parts of their identities upon their participation in esports, how participants view themselves in comparison to how those outside of esports view them, and what roles participants might fill within the larger categories of player or tournament host. Specifically, the process of hosting events and how that impacts those hosts' participation is worthy of future study.

Another avenue for future study is the effects of different demographic characteristics on participation as this study was quite homogenous in its sample. As such it did not attempt to analyze any diversity in gender, race, ethnicity, or another factor that had an impact on socialization into or socialization through participation. Specifically, the effect of age should also be considered for future studies. Even though this study had the most variance when it came to age, the scope of this study was not well equipped to study the effects of age on participation. Most likely, age plays a role in specialization. This study did not include any interviewees who were women. The role gender plays in esports is particularly of interest due to the recent revelations of the sexual misconduct happening in the gaming industry as a whole (Lorenz \& Browning 2020). Lastly, studies building upon this one can use this as a foundation to analyze the differences between leisure-based and professional esports participation.

The competitive-social spectrum of participation within leisure-based esports was found late in the process of analysis. Because of this, there were no questions to 
interviewees that could have allowed the concept to be more elaborated. It is a concept that may hold weight or there may be better ways to explain it. It takes influence from the leisure experience perspective continuum and may work better as a complement to that rather than a standalone concept. Regardless, the spectrum is something worth considering in future research, especially those that would more deeply analyze the concept. Building off of this study directly this researcher foresees a quantitative approach to understand if the findings of this study are transferrable to different in-groups nationwide through a survey. 


\section{REFERENCES}

Brehm, Audrey L. 2013. "Navigating the Feminine in Massively Multiplayer Online Games: Gender in World of Warcraft." Frontiers in Psychology 4(903). doi: 10.3389/fpsyg.2013.00903.

Bryan, H. Norman. 1977. "Leisure Value Systems and Recreational Specialization: The Case of Trout Fisherman." Journal of Leisure Research 9(3):174-87.

Bryan, H Norman. 2000. "Recreation Specialization Revisited.” Journal of Leisure Research 32(1):18-21.

Burk, Dan L. 2013. "Owning E-Sports: Proprietary Rights in Professional Computer Gaming." University of Pennsylvania Law Review 161(6):1535-1578.

Carlson, Chad. 2018. "A Three-Pointer: Revisiting Three Crucial Issues in the 'Tricky Triad' of Play, Games, and Sport.” Pp. 3-21 in Defining Sport: Conceptions and Borderlines, edited by Shawn E. Klein. Lanham, MD: Lexington Books.

Charmaz, Kathy. 2013. Constructing Grounded Theory A Practical Guide Through Qualitative Analysis. London: Sage Publications LTD.

Coakley, J. 2015. Sports in Society: Issues and Controversies. $11^{\text {th }}$ ed. New York: McGraw-Hill.

Csikszentmihalyi, M. 1990. Flow: The psychology of optimal experience. New York: Harper \& Row.

Dannefer, Dale. 1981. "Neither Socialization nor Recruitment: The Avocational Careers of Old-Car Enthusiasts." Social Forces 60(2):395-413.

Edginton. Christopher R, Donald G. Degraaf, Susan Edginton, and Debra J. Jordan. 2002. Leisure and Life Satisfaction. New York, NY; McGraw-Hill.

Freeman, Guo, and Donghee Yvette Wohn. 2018. "Understanding eSports Team Formation and Coordination." Computer Supported Cooperative Work: The Journal of Collaborative Computing 27(3-6):1019-1050.

Havrilesky, Thomas. 1972. "The Information Explosion, Technological Innovativeness and the Competitive Ethic." Land Economics 48(4):347-356.

Henderson, Karla. 2010. "Importance of Leisure to Individuals and Society." Pp. 3-26 Dimensions of Leisure for Life: Individuals and Society, edited by Gayle Kassing, Bethany J. Bentley, Ray Vallese, Derek Campbell, and Julie Anderson. Human Kinetics: Champaign, IL. 
Hughes, Robert and Jay Coakley. 1991. "Positive Deviance Among Athletes: The Implications of Overconformity to the Sport Ethic.” Sociology of Sport Journal 8(4):307-325.

Kleiber, Doublas A., Gordon J. Walker, and Roger C. Mannell. 2011. A Social Psychology of Leisure, 2nd edition. State College, PA: Venture Publishing.

Lorenz, Taylor ad Kellen Browning. 2020. "Dozens of Women in Gaming Speak Out About Sexism and Harassment.” Retrieved April 26, 2021 (https://www.nytimes.com/2020/06/23/style/women-gaming-streamingharassment-sexism-twitch.html).

Mannell, Roger C. and Douglas A. Kleiber. 1997. A Social Psychology of Leisure. State College, PA: Venture Publishing.

Scott, David and C. Scott Shafer. 2001. "Recreational Specialization: A Critical Look at the Construct." Journal of Leisure Research 33(3):319-343.

Stebbins, R.A. 1997. “Casual Leisure: A conceptual statement.” Leisure Studies 16(1):17-25.

Stebbins, R.A. 2001. “Serious Leisure.” Society 38(4):53-57.

Stebbins, R.A. 2015. Serious Leisure: A Perspective for Our Time. New Brunswick, New Jersey: Transaction Publishers.

Taylor, Nicholas Thiel. 2016. "Now you're playing with audience power: the work of watching games." Critical Studies in Media Communication 33(4):293-307.

Taylor, T.L. 2012. Raising the Stakes: E-Sports and the Professionalization of Computer Gaming. Cambridge, MA: The MIT Press.

Veal, A.J. 2017. "The Serious Leisure Perspective and the Experience of Leisure." Leisure Sciences 39(3):205-223.

World Health Organization. 2018. "Addictive Behaviours: Gaming Disorder.” Retrieved April 26, 2021 (https://www.who.int/news-room/q-a-detail/addictive-behavioursgaming-disorder). 


\section{APPENDICES}

Demographic Table

\begin{tabular}{|c|c|}
\hline Total Interviewees & 10 \\
\hline \multicolumn{2}{|l|}{ Age } \\
\hline $18-20$ & 3 \\
\hline $21-25$ & 2 \\
\hline $26-30$ & 2 \\
\hline $31-35$ & 3 \\
\hline \multicolumn{2}{|l|}{ Gender } \\
\hline Men & 10 \\
\hline \multicolumn{2}{|c|}{ Race \& Ethnicity (Not Mutually Exclusive) } \\
\hline Caucasian & 7 \\
\hline Hispanic & 2 \\
\hline Latino & 2 \\
\hline Native American & 2 \\
\hline African American & 1 \\
\hline Middle Eastern & 1 \\
\hline \multicolumn{2}{|c|}{ Household Income for the past 12 Months } \\
\hline Less Than $\$ 30,000$ & 0 \\
\hline
\end{tabular}




\begin{tabular}{|c|c|}
\hline$\$ 30,000$ up to $\$ 49,999$ & 2 \\
\hline$\$ 50,000$ up to $\$ 99,999$ & 5 \\
\hline$\$ 100,000$ up to $\$ 349,999$ & 2 \\
\hline$\$ 350,000$ and over & 1 \\
\hline
\end{tabular}




\section{Interview Guide}

1) Tell me about how you learned of esports.

2) What about esports made you want to participate in them?

a. When did you begin to participate in esports?

3) Was anyone or anything especially influential when you first started participating?

a. How did they help you?

4) Is anyone or anything now especially influential to your participation?

a. How do they help you?

5) Tell me about anything that has gotten in the way of your participation in esports.

6) How do people react when they learn that you participate in esports?

a. How do you feel about their reaction (to your participation)?

7) Has participating in esports changed you over time? If so, tell me how.

8) What benefits have you gotten out of participating in esports?

9) In what ways do you feel that you are - or are not - a part of a community based around esports?

10) What are your motivations for continuing to participate in esports? 
a. Do they come from yourself or others?

11) What do you think the future holds for you in esports?

12) Tell me how the COVID-19 pandemic has affected your participation in esports, if at all. 


\title{
CURRICULUM VITAE
}

\author{
Name: Joseph Brewer \\ Email Address: $\quad$ joseph.brewer.1@louisville.edu \\ Education: $\quad$ B.A. Sociology from University of Louisville - May 2019 \\ MA Sociology from University of Louisville - Expected May \\ 2020 \\ Thesis Title: $\quad$ Exploring Socialization Processes for Leisure-Based Esports: A \\ Qualitative Study \\ Teaching Experience: Intro to Sociology - Fall 2019 \\ Intro to Sociology - Fall 2020 \\ Skills: $\quad$ Stata \\ Qualitative Analysis \\ Survey Research
}

